\title{
PTEN hamartoma tumour syndrome: variability of an entity
}

\author{
J H M Merks, L S de Vries, X-P Zhou, P Nikkels, P G Barth, C Eng, R C M Hennekam
}

J Med Genet 2003;40:e111 (http://www.jmedgenet.com/cgi/content/full/40/10/el11)

C owden syndrome (CS; OMIM 158350) is an autosomal dominant disorder with age related penetrance characterised by mucocutaneous lesions, macrocephaly and an increased risk of cancer, especially of the breast, thyroid and endometrium. ${ }^{12}$ The phenotype in CS has proven to be highly variable, which became especially evident after identification of the susceptibility gene PTEN. ${ }^{3}$ This is also shown in the change in incidence figures, which were found to be at least five times higher after PTEN was identified (estimated incidence before PTEN identification 1:1 000 000, ${ }^{5}$ and after $>1: 200000 \cdot{ }^{67}$ ). Bannayan-Riley-Ruvalcaba syndrome (BRRS; OMIM 153480) is allelic to CS and is characterised by the triad of macrocephaly, lipomas, and pigmented macules of the glans penis. ${ }^{8}$ Proteus syndrome (PS; OMIM 176920) is a disorder characterised by overgrowth of hands and/or feet, asymmetry of limbs, connective tissue, and epidermal naevi, vascular and lymphatic malformations, and cranial hyperostosis. ${ }^{8}$ Proteus-like syndrome (PLS) is another closely related disorder, where individuals are characterised by the presence of macrocephaly, lipomas and overgrowth not meeting the criteria for CS, BRRS, or PS. ${ }^{8}$ Germline PTEN mutations have been found in $80 \%$ of individuals with CS, $60 \%$ of individuals with BRRS, up to $20 \%$ with PS, and $50 \%$ with PLS. ${ }^{10}$

Here, we present a family (a mother and three sons) in which phenotype was extremely variable, one member having macrocephaly, normal intelligence, and minimal pigmentation abnormalities; another member with macrocephaly with developmental delay; another with macrocephaly, delay and lipoma; and the last member having hemimegalencephaly (HME), Jadassohn naevus sebaceous, and neonatal demise. All were found to have the same germline mutation in PTEN.

\section{CASE REPORTS \\ Case 1}

The proband was the thirdborn child of non-consanguineous parents. His two older sisters were healthy. Prenatal routine sonography showed a unilateral ventricular dilatation. He was born preterm at 32 2/7 weeks, possibly in part because of the positive discrepancy due to the macrocephaly. Weight at birth was $2620 \mathrm{~g}$ (97th centile) and occipitofrontal circumference (OFC) was $38 \mathrm{~cm}(5 \mathrm{~cm}>98$ th centile). APGAR scores were 4 and 5 after 1 and 5 min, respectively. Respiratory insufficiency urged immediate artificial ventilation. Physical examination showed his skull to be severely asymmetric, bulging to the left, and there were ipsilateral linear naevi on nose and forehead (fig 1A). He developed hemiconvulsions, which did not respond to therapy and caused progressive cardiorespiratory problems. Ultrasonography and computed tomography (CT) scanning of the brain showed ipsilateral hemimegalencephaly, irregular lateral ventricular dilatation and periventricular calcifications adjacent to the dilated ventricle (fig 1B). The seizures were uncontrollable and eventually led to an early demise on the third day of life. Autopsy showed left sided unilateral megalencephaly (total brain weight $510 \mathrm{~g}$; normal for

\section{Key points}

- Cowden syndrome (CS), Bannayan-Riley-Ruvalcaba syndrome (BRRS), proteus and proteus-like syndrome are entities that can show remarkable clinical overlap, and are all shown to be caused by germline PTEN mutations $180 \%$ of CS cases, $60 \%$ of BRR cases, up to $20 \%$ of Proteus syndrome cases, and $50 \%$ of Proteuslike cases).

- We describe four members of a single family with a heterogeneous phenotype that at present most closely fits BRRS, although further development of symptoms with time may eventually lead to the diagnosis of CS.

- All four cases were shown to harbour the same PTEN mutation (IVS5+1 delG).

- One of the cases was first suspected of having Jadassohn naevus sebaceous syndrome, a diagnosis that was refuted only after the birth of the other family members and PTEN mutation analysis. This patient also had a hemimegalencephaly, not reported before in a case with BRRS or CS. No loss of heterozygosity was found in the megalencephalic part of the brain.

- The family can best be classified by the molecular cause as having PTEN hamartoma tumour syndrome. Hemimegalencephaly as part of Jadassohn naevus sebaceous syndrome can be added as further manifestations of germline PTEN mutations.

gestational age $217 \mathrm{~g}$ (SD $49 \mathrm{~g})$ ), periventricular cysts and an extremely thick cortex, the left side showing pachygyria (fig 1C). Microscopy of this side of the brain showed haphazardly arranged neurones, lacking the normal arrangement in six layers. The child was diagnosed as having Jadassohn naevus sebaceous (OMIM 163200). ${ }^{8}$ The parents were given a low recurrence risk for similar problems in future offspring.

\section{Case 2}

Case 2 was born at term after an uneventful pregnancy. His large head caused a cephalopelvic discrepancy, making a vacuum extraction necessary. APGAR scores were 3 and 9 after $\mathrm{l}$ and $5 \mathrm{~min}$, respectively. His weight was $4720 \mathrm{~g}$ (>97th centile) and OFC was $38.5 \mathrm{~cm}(2 \mathrm{~cm}>98$ th centile). Brain ultrasonography in the neonatal period showed dilated lateral ventricles. His height increased following the 50th centile, his macrocephaly persisted, remaining at $>98$ th

Abbreviations: BRRS, Bannayan-Riley-Ruvalcaba syndrome; CS, Cowden syndrome; $\mathrm{CT}$, computed tomography; EEG, electroencephalograph; HME, hemimegalencephaly; MRI, magnetic resonance imaging; OFC, occipitofrontal circumference; PHTS, PTEN hamartoma tumour syndrome; PLS, Proteus-like syndrome 
centile. He had a single febrile convulsion at 9 months of age. At 12 months of age, he was first seen because of mild developmental delay and his elder brother's diagnosis of Jadassohn naevus sebaceous. His cognition was estimated to be normal, but his motor development was delayed. Physical examination showed the macrocephaly and a bicoloured left iris (fig 2A). His development remained somewhat delayed thereafter, although he was able to attend regular education. Formal intelligence testing showed his IQ to be at the lower range of normal. Around 30 months of age, he developed two lipomata, one on his left lower abdomen, the other in the right paravertebral area. Both were surgically removed. At the age of 36 months, he was found to have absences and atonic seizures. Electroencephalograph (EEG) studies revealed bitemporal focal anomalies, but no spikes. Other electrophysiological studies (electromyography, electroretinography, visual evoked potentials, and brainstem evoked potentials) gave normal results, as did sonography of the kidneys. A full metabolic screening of urine, plasma, and spinal fluid did not show any abnormality. The brain magnetic resonance imaging (MRI) scan demonstrated dilated lateral ventricles, widened perivascular spaces but otherwise a normal cortical architecture.

\section{Case 3}

The third brother presented to us at the age of 9 years because of developmental delay, macrocephaly, and the family history. Pregnancy and delivery were uneventful. Weight at birth was $4750 \mathrm{~g}$. (>97th centile), OFC was $37 \mathrm{~cm}$ (98th centile). He had a slow psychomotor development, being able to walk at the age of 3.5 years. He entered special schooling. At physical examination at 9 years, he had an OFC of $60 \mathrm{~cm}$ (3.5 cm >98th centile) with a prominent forehead, but otherwise no minor anomalies, neurological, or skin abnormalities (fig 2B). EEG studies and brain MRI scanning gave normal results.

\section{Case 4}

The mother of the three boys was of Caucasian descent. Pregnancy and delivery were uneventful. No reliable data on body measurements in the neonatal period were available. She stated that she had always had a large head circumference. Her cognitive development had been normal, and she followed normal schooling. At the age of 35 years, she was found to be macrocephalic (OFC $63.2 \mathrm{~cm} ; 4 \mathrm{~cm}>98$ th centile). Her skin had pigmentation abnormalities (fig 2C), and she had large breasts. Sonography showed multiple mammary cysts. A complete examination failed to show any other signs or symptoms of CS.

Her family history showed that she had two brothers, both with unusually large heads, even as children. They were not available for further investigations. History revealed that the patient's mother had had a normal head size, and no specific pigmentation abnormalities. The patient's father had had a very large head, necessitating him to order custom made hats if needed. He was not known to have had pigmentation anomalies. The father, who was a smoker, developed fatal lung carcinoma at the age of 68 years, with secondary brain metastasis. No reliable data on other family members were available.

\section{MOLECULAR STUDIES}

Because of the combination of macrocephaly (4/4), pigmentation anomalies $(2 / 4)$, megalencephaly $(2 / 4)$, lipoma $(1 / 4)$, and developmental problems $(2 / 3$ in this single family), a leading diagnosis was CS/BRRS, and PTEN mutation analysis was performed, after appropriate informed consent. The mother and her three affected sons all showed the same germline PTEN mutation, IVS5+ldelG (case 1: liver tissue; all others: lymphocytes). As the hemimegalencephalic part of
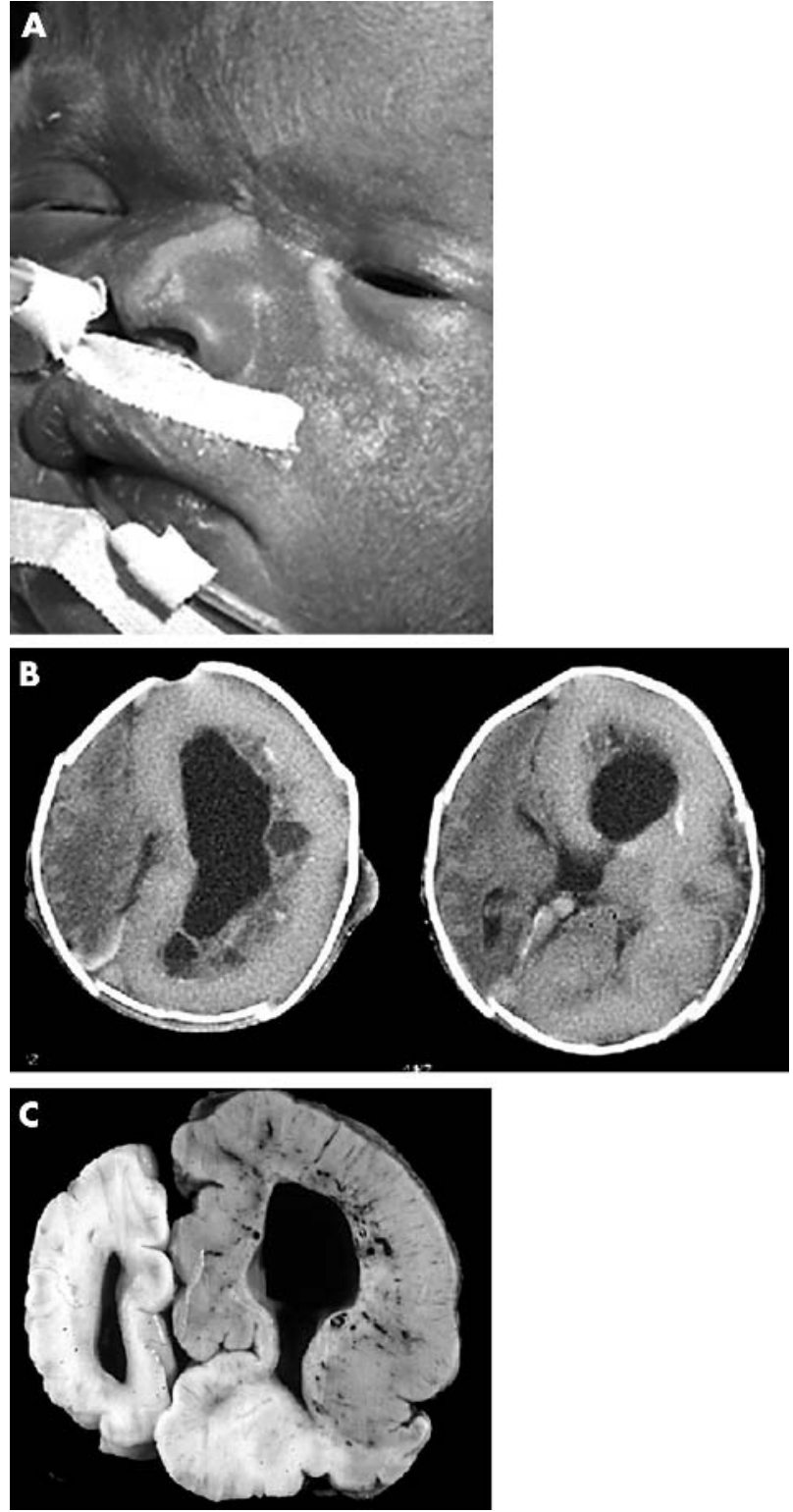

Figure 1 Case 1. (A) Linear naevi on the nose and below the left eye, ipsilateral to the hemimegalencephaly. (B) CT scan of the brain, showing hemimegalencephaly, irregular lateral ventricular dilatation and periventricular calcifications adjacent to the dilated ventricle. This picture was published earlier. ${ }^{27}$ (C) Autopsy showed left sided unilateral megalencephaly, periventricular cysts and an extremely thick cortex, the left side showing pachygyria.

the brain of case 1 might have arisen due to loss of the remaining wild-type allele (loss of heterozygosity; LOH), mutation analysis was performed in a biopsy of the autopsy material. However, no $\mathrm{LOH}$ was found.

\section{DISCUSSION}

We describe a family in which four different members had findings that fitted CS/BRRS and who were all shown to harbour a germline PTEN mutation. This germline PTEN mutation, IVS5+ldelG, has been reported at least once before in a proband with CS. ${ }^{11}$ The deletion of one of the two canonical splice signals is predicted to result in an aberrant splice, and thus, is almost certainly pathogenic. Owing to the presence of linear verrucous pigmented naevi and hemimegalencephaly, case l was first suspected of having Jadassohn naevus sebaceous syndrome, ${ }^{8}$ a clinical diagnosis 

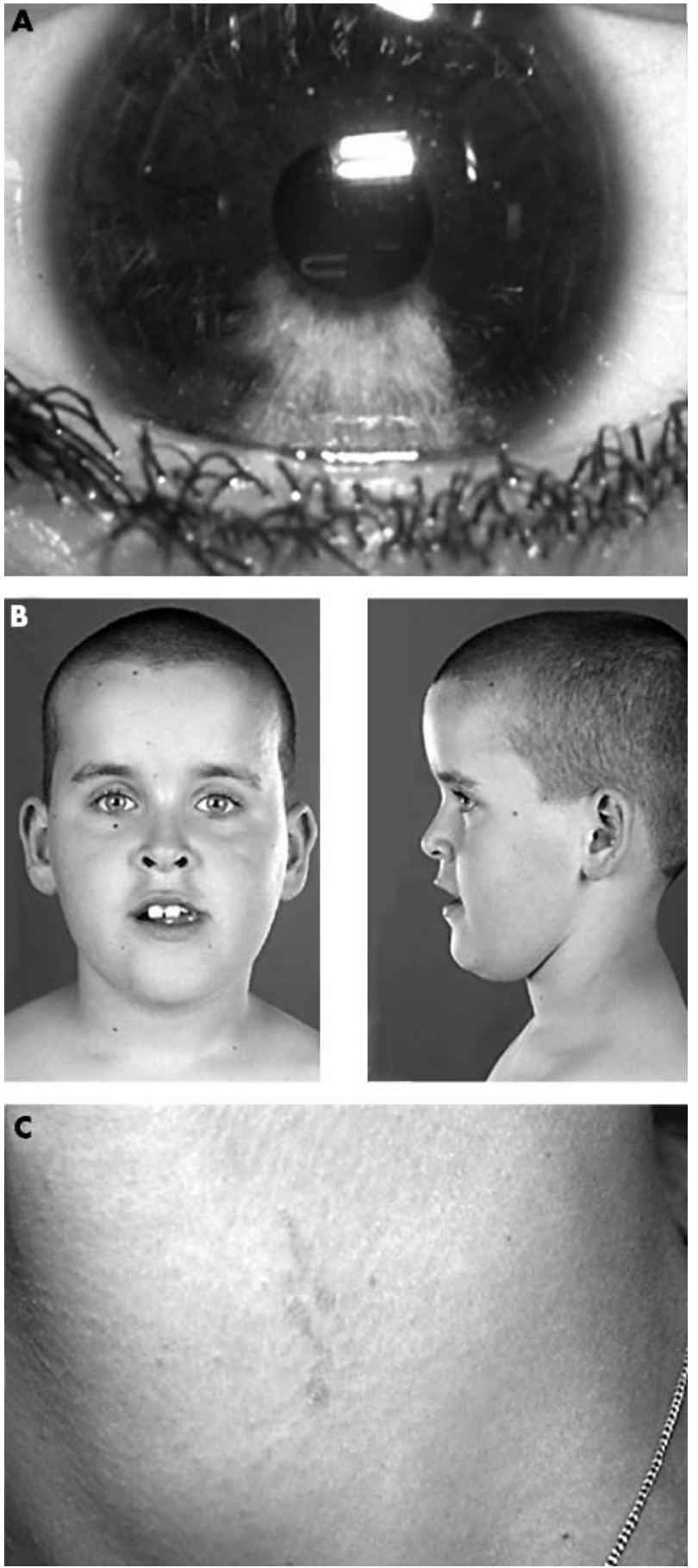

Figure 2 (A) Bicoloured left iris (case 2), not reported previously in a Cowden syndrome/Bannayan-Riley-Ruvalcaba syndrome patient; (B) macrocephaly and prominent forehead (case 3); (C) pigmentation abnormalities of the skin (case 4).

that was disproved only after the birth of the other affected siblings and the molecular PTEN analysis. We have tested two other affected patients with Jadassohn naevus sebaceous syndrome, but did not find a PTEN mutation in them (Eng and Hennekam, unpublished data). The HME in case 1 is unusual and has not been reported previously in a case with CS/BRRS. Flores-Sarnat reviewed HME and proposed a system of classification into three types: isolated HME, syndromic HME and total HME. ${ }^{12}$ The present case 1 should be classified as having the syndromic type. HME was found to have a heterogeneous cause, as several neurocutaneous syndromes presenting with HME have been described. To this, CS/BRRS can be added.

Hamartomas in CS affect derivatives of all three germ layers, ${ }^{13}$ but it is not clear why overgrowth in PTEN hamartoma tumour syndrome (PHTS) (for example, Proteus syndrome) may be patchily distributed. This may be dependent on the pattern of genetic and epigenetic alterations subsequent to the germline mutation. ${ }^{14}$ Mutation analysis of autopsy material of the brain of case 1 did not show LOH of PTEN. This is in line with the results reported by other groups where LOH was found in different percentages in tumours and hamartomas: LOH was found in 130/145 cases with informative tumours, ${ }^{15}$ in all four tested tumours from one individual, ${ }^{16}$ in $3 / 11$ CS individuals with 20 hamartoma, ${ }^{17}$ and in $4 / 6$ skin hamartomas from one CS individual. ${ }^{18}$

The operational diagnostic criteria for CS have been revised in 2000 by the International Cowden Consortium. ${ }^{1}$ In the present family, no single case fulfilled these criteria. However, the typical skin findings pathognomonic for CS usually develop only in the second decade of life (or later), and three out of four family members were younger than 10 years old. The same principle applies for the increased cancer risk. If the findings of all family members were taken together, then they become closer to the criteria. The family can also be classified clinically as BRRS. ${ }^{10}{ }^{14} 19$ Recently three patients with benign familial macrocephaly (macrocephaly and delayed motor milestones) were reported to harbour a PTEN mutation, one of these patients having a juvenile polyp. ${ }^{20}$ Together with the present observation, this points to a wider indication for the performance of PTEN mutational analyses. Therefore, with the broadening clinical spectra associated with germline PTEN mutations, it has become more useful to use a molecular based approach; an individual found to carry a germline PTEN mutation should be classified as having PHTS, irrespective of clinical presentation. ${ }^{19}$ Clinicians are urged to manage all PHTS individuals as having CS with respect to cancer risk and surveillance. The increased risk in CS of developing malignancies mainly involves breast cancer, epithelial thyroid cancer, and endometrial carcinoma. ${ }^{12122}$ The risk for breast cancer is increased in $\mathrm{CS}^{23-26}$, and there is also a lowering of the mean age at diagnosis, 10 years (or more) earlier compared with the general population. ${ }^{23}{ }^{25}$ The mother of the present proband is now being screened for cancer according to the guidelines of the NCCN. ${ }^{2}$ Her affected sons will enter the screening program at 18 years of age.

In conclusion, we have found a germline PTEN mutation in a family in which none of the individual affected members fulfilled the international diagnostic criteria for CS. In the presence of a PTEN mutation, the family can be classified as having PHTS, with all implications for further medical management. Hemimegalencephaly as part of Jadassohn naevus sebaceous syndrome may be another phenotypic finding associated with germline PTEN mutation.

\section{ACKNOWLEDGEMENTS}

We thank E H Hoefsloot (Laboratory for molecular diagnostics, Nijmegen) for additional help in studying this family. C Eng is a Doris Duke Distinguished Clinical Scientist and is partially supported by the American Cancer Society (RSG-02-151-0 CCE).

\section{Authors' affiliations}

J H M Merks, Department of Paediatric Oncology, Emma Children's Hospital, Academic Medical Centre, Amsterdam, The Netherlands L S de Vries, Department of Neonatology Wilhelmina Children's Hospital, Utrecht Medical Centre, the Netherlands

P Nikkels, Department of Pathology, Wilhelmina Children's Hospital, Utrecht Medical Centre, The Netherlands 
P G Barth, Department of Paediatric Neurology, Emma Children's Hospital, Academic Medical Centre, Amsterdam, The Netherlands X-P Zhou, C Eng, Clinical Cancer Genetics Program and Human Cancer Genetics Program, Comprehensive Cancer Centre, Division of Human Genetics, Department of Internal Medicine, The Ohio State University, Columbus, Ohio, USA

R C M Hennekam, Department of Paediatrics and Institute for Human Genetics, Emma Children's Hospital, Academic Medical Centre, Amsterdam, The Netherlands

Correspondence to: Dr Hans Merks, Department of Paediatric Oncology, Floor F8-Room 245, Emma Children's Hospital-Academic Medical Centre, Meibergdreef 9, 1105 AZ Amsterdam, The Netherlands; j.h.merks@amc.uva.nl

\section{REFERENCES}

1 Eng C. Will the real Cowden syndrome please stand up: revised diagnostic criteria. J Med Genet 2000;37:828-30.

2 National Comprehensive Cancer Network. NCCN practice guidelines: genetics/familial high risk cancer, 1999, revised 2002 http://www.nccn.org.

3 Liaw D, Marsh DJ, Li J, Dahia PL, Wang SI, Zheng Z, Bose S, Call KM. Tsou HC, Peacocke M, Eng C, Parsons R. Germline mutations of the PTEN gene in Cowden disease, an inherited breast and thyroid cancer syndrome. Nat Genet 1997;16:64-7.

4 Marsh DJ, Coulon V, Lunetta KL, Rocca-Serra P, Dahia PL, Zheng Z, Liaw D, Caron S, Duboue B, Lin AY, Richardson AL, Bonnetblanc JM, Bressieux JM, Cabarrot-Moreau A, Chompret A, Demange L, Eeles RA, Yahanda AM, Fearon ER, Fricker JP, Gorlin RJ, Hodgson SV, Huson S, Lacombe D, Le Prat F, Odent S, Toulouse C, Olopade OI, Sobol H, Tishler S, Woods CG Robinson BG, Weber HC, Parsons R, Peacocke M, Longy M, Eng C, et al. Mutation spectrum and genotype-phenotype analyses in Cowden disease and Bannayan-Zonana syndrome, two hamartoma syndromes with germline PTEN mutation. Hum Mol Genet 1998;7:507-15.

5 Nelen MR, Padberg GW, Peeters EA, Lin AY, van den Helm B, Frants RR, Coulon V, Goldstein AM, van Reen MM, Easton DF, Eeles RA, Hodgsen $S$ Mulvihill JJ, Murday VA, Tucker MA, Mariman EC, Starink TM, Ponder BA, Ropers $\mathrm{HH}$, Kremer $\mathrm{H}$, Longy M, Eng C. Localization of the gene for Cowden disease to chromosome 10q22-23. Nat Genet 1996;13:114-16.

6 Nelen MR, van Staveren WC, Peeters EA, Hassel MB, Gorlin RJ, Hamm H, Lindboe CF, Fryns JP, Sijmons RH, Woods DG, Mariman EC, Padberg GW, Kremer $\mathrm{H}$. Germline mutations in the PTEN/MMACl gene in patients with Cowden disease. Hum Mol Genet 1997;6:1383-7.

7 Nelen MR, Kremer H, Konings IB, Schoute F, van Essen AJ, Koch R, Woods CG, Fryns JP, Hamel B, Hoefsloot LH, Peeters EA, Padberg GW. Novel PTEN mutations in patients with Cowden disease: absence of clear genotypephenotype correlations. Eur J Hum Genet 1999;7:267-73.

8 Gorlin RJ, Cohen MM, Hennekam RC. Syndromes of the head and neck, 4th ed. Oxford: Oxford University Press, 2001.

9 Marsh DJ, Kum JB, Lunetta KL, Bennett MJ, Gorlin RJ, Ahmed SF, Bodurtha J, Crowe C, Curtis MA, Dasouki M, Dunn T, Feit $\mathrm{H}$, Geraghty MT, Graham JM Jr, Hodgson SV, Hunter A, Korf BR, Manchester D, Miesfeldt S, Murday VA, Nathanson KL, Parisi M, Pober B, Romano C, Tolmie JL, Trembath R, Winer RM, Zackai EH, Zori RT, Wneng LP, Dahia PLM, Eng C, et al. PTEN mutation spectrum and genotype-phenotype correlations in Bannayan-RileyRuvalcaba syndrome suggest a single entity with Cowden syndrome. Hum Mol Genet 1999;8:1461-72.

10 Zhou X, Hampel H, Thiele H, Gorlin RJ, Hennekam RC, Parisi M, Winter RM, Eng C. Association of germline mutation in the PTEN tumour suppressor gene and Proteus and Proteus-like syndromes. Lancet 2001;358:210-11.

11 Waite KA, Eng C. Protean PTEN: form and function. Am J Hum Genet 2002;70:829-44.

12 Flores-Sarnat L. Hemimegalencephaly: part 1. Genetic, clinical, and imaging aspects. J Child Neurol 2002;17:373-84.

13 Gimm O, Attie-Bitach T, Lees JA, Vekemans M, Eng C. Expression of the PTEN tumour suppressor protein during human development Hum Mol Genet 2000;9:1633-9

14 Zhou XP, Marsh DJ, Hampel H, Mulliken JB, Gimm O, Eng C. Germline and germline mosaic PTEN mutations associated with a Proteus-like syndrome of hemihypertrophy, lower limb asymmetry, arteriovenous malformations and lipomatosis. Hum Mol Genet 2000;9:765-8.

15 Bonneau D, Longy M. Mutations of the human PTEN gene. Hum Mutat 2000;16:109-22.

16 Lynch ED, Ostermeyer EA, Lee MK, Arena JF, Ji H, Dann J, Swisshelm K, Suchard D, MacLeod PM, Kvinnsland S, Gjertsen BT, Heimdal K, Lubs H, Moller P, King MC. Inherited mutations in PTEN that are associated with breast cancer, cowden disease, and juvenile polyposis Am J Hum Genet 1997:61:1254-60.

17 Marsh DJ, Dahia PL, Coulon V, Zheng Z, Dorion-Bonnet F, Call KM, Little R, Lin AY, Eeles RA, Goldstein AM, Hodgson SV, Richardson AL, Robinson BG, Weber HC, Longy M, Eng C. Allelic imbalance, including deletion of PTEN/ $\mathrm{MMACl}$, at the Cowden disease locus on 10q22-23, in hamartomas from patients with Cowden syndrome and germline PTEN mutation. Genes Chromosomes Cancer 1998;21:61-9.

18 Trojan J, Plotz G, Brieger A, Raedle J, Meltzer SJ, Wolter M, Zeuzem S. Activation of a cryptic splice site of PTEN and loss of heterozygosity in benign skin lesions in Cowden disease. J Invest Dermatol 2001;117:1650-3.

19 Gorlin RJ, Cohen MM Jr, Condon LM, Burke BA. Bannayan-Riley-Ruvalcaba syndrome. Am J Med Genet 1992:44:307-14.

20 Temple IK, Lachlan KL, Dennis NR, Lucassen AM, Collins AL, Eccles DM, Bunyan D. Benign familial macrocephaly - the Wessex PTEN experience et al. 10th Manchester Birth Defects Conference. 2002.

21 Marsh DJ, Dahia PL, Caron S, Kum JB, Frayling IM, Tomlinson IP, Hughes KS Eeles RA, Hodgson SV, Murday VA, Houlston R, Eng C. Germline PTEN mutations in Cowden syndrome-like families. J Med Genet 1998;35:881-5.

22 De Vivo I, Gertig DM, Nagase S, Hankinson SE, O'Brien R, Speizer FE, Parsons R, Hunter DJ. Novel germline mutations in the PTEN tumour suppressor gene found in women with multiple cancers. J Med Genet 2000;37:336-41

23 Starink TM, van der Veen JP, Arwert F, de Waal LP, de Lange GG, Gille JJ, Eriksson AW. The Cowden syndrome: a clinical and genetic study in 21 patients. Clin Genet 1986;29:222-33.

24 Hanssen AM, Fryns JP. Cowden syndrome. J Med Genet 1995;32:117-19.

25 Longy M, Lacombe D. Cowden disease. Report of a family and review. Ann Genet 1996:39:35-42.

26 Eng C. Cowden syndrome. J Genet Couns 1997;6:181-91.

27 Ernst MR, Pekelharing M, Gooskens RHJM, Breslau-Siderius EJ, De Vries LS. Neonatale convulsies: niet altijd asfyxie. Tiidschrift voor Kindergeneeskunde 1997;65:259-64. 